\title{
ИНТЕЛЛЕКТУАЛИЗАЦИЯ ТРУДА, КАК ФАКТОР ПОВЫШЕНИЯ КОНКУРЕНТОСПОСОБНОСТИ НА ГОРНОДОБЫВАЮЩИХ ПРЕДПРИЯТИЯХ
}

\section{INTELLECTUALIZATION OF LABOR AS A FACTOR OF INCREASING COMPETITIVENESS IN MINING ENTERPRISES}

\section{N. Izosimov}

Summary. The scientific article is devoted to the research analysis of the characteristics of the processes of intellectualization of labor of working personnel, as a key factor in the management and increasing the competitiveness of enterprises in the mining industry of the economy of the Russian Federation. The relevance of the study is due to the fact that today the level of labor productivity of human resources of the country's mining enterprises is at a low level. Accordingly, there is an urgent need to develop measures and adopt mechanisms to improve labor efficiency, which is possible through the introduction of digital technologies and the professional development of intelligent talented employees. Within the framework of the article, the current problems of ensuring a high level of labor productivity by enterprises of the mining industry of the Russian economy are analyzed. The theoretical aspects of the concepts of "management of competitiveness", "labor productivity" and "intellectualization of labor" are considered. The promising directions for the development of the system of labor intellectualization, which can contribute to the improvement of the quality of labor and the development of personnel, are attached. The mechanisms of development of the system of intellectualization of labor through professional training of personnel are considered.

Keywords: intellectualization of labor, labor productivity, labor efficiency, mining enterprise, mining industry, staff development, digital technologies, increasing competitiveness, training. $\mathbf{y}$ правление трудовыми ресурсами является политикой или внутренней функцией организации, которая сосредоточена на наборе, управлении и обеспечении деятельности людей, которые работают в организации. Все процессы и программы, которые затрагивают человеческую деятельность, являются частью системы управления человеческими ресурсами предприятия [1].

Актуальность научного исследования на тематику «интеллектуализация труда, как фактор повышения конкурентоспособности на горнодобывающих пред-
Изосимов Никита Павлович

Аспирант, Российская академия народного хозяйства и государственной службы при Президенте Российской Федерации Nikitaizosimov@gmail.com

Аннотация. Научная статья посвящена проведению исследовательского анализа характеристики процессов интеллектуализации труда рабочего персонала, как ключевого фактора в управлении и повышении конкурентоспособности предприятий горнодобывающей промышленности экономики Российской Федерации. Актуальность исследования обусловлена тем, что на сегодняшний день уровень производительности труда человеческих ресурсов горнодобывающих предприятий страны находится на низком уровне. Соответственно, формируется острая необходимость разработки мероприятий и принятия механизмов повышения эффективности труда, что возможно при помощи внедрения цифровых технологий и профессионального развития интеллектуальных способной сотрудников. В рамках статьи проанализированы актуальные проблемы обеспечения высокого уровня производительности труда предприятиями горнодобывающей промышленности российской экономики. Рассмотрены теоретические аспекты понятия «управление конкурентоспособностью», «производительность труда» и «интеллектуализация труда. Приложены перспективные направления развития системы интеллектуализации труда, которые могут поспособствовать повышению качества труда и развития персонала. Рассмотрены механизмы развития системы интеллектуализации труда через профессиональное обучение персонала.

Ключевые слова: интеллектуализация труда, производительность труда, эффективность труда, горнодобывающее предприятие, горнодобывающая промышленность, развитие персонала, цифровые технологии, повышение конкурентоспособности, обучение персонала.

приятиях» обусловлена тем, что на сегодняшний день уровень производительности труда человеческих ресурсов горнодобывающих предприятий страны находится на низком уровне. Соответственно, формируется острая необходимость разработки мероприятий и принятия механизмов повышения эффективности труда, что возможно при помощи внедрения цифровых технологий и профессионального развития интеллектуальных способной сотрудников.

По этой причине, целью научной статьи выступает проведение исследовательского анализа характери- 


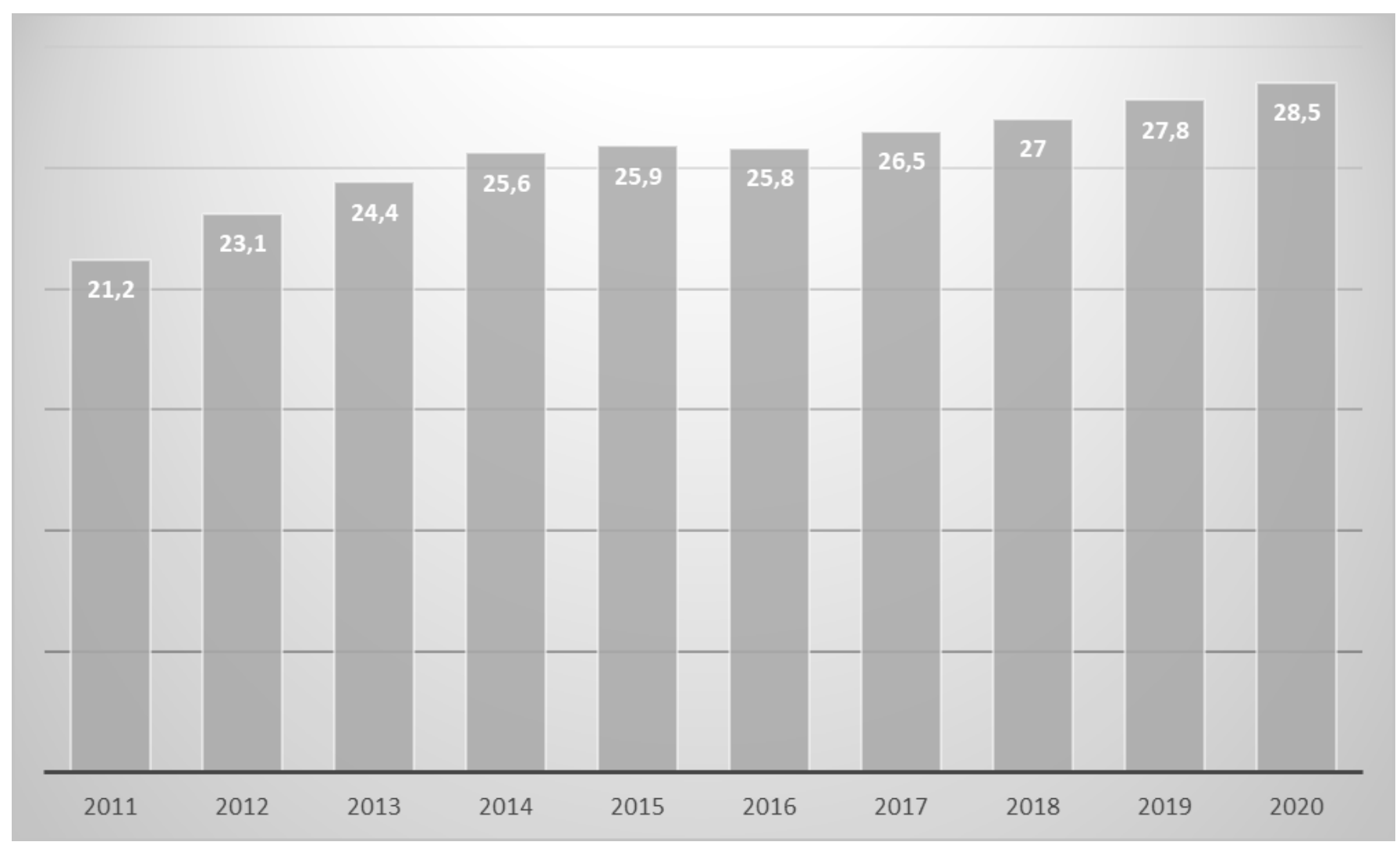

Рис. 1. Динамика уровня производительности труда в России [2].

стики процессов интеллектуализации труда рабочего персонала, как ключевого фактора в управлении и повышении конкурентоспособности предприятий горнодобывающей промышленности экономики Российской Федерации.

На сегодняшний день актуальными проблемами обеспечения высокого уровня производительности труда предприятиями горнодобывающей промышленности российской экономики выступают [3; 4]:

- высокая текучесть кадров;

- низкий уровень профессионализма человеческих ресурсов в управлении персоналом;

- применение диктатуры и авторитарной системы управления со стороны руководителей по отношению к своему рабочему персоналу;

- низкая эффективность мотивационной системы, в том числе, высокая дифференциация оплаты труда и отсутствие нематериальных стимулов;

- низкий уровень автоматизации процессов HR-отдела предприятия.

Исходя из этого, формируется необходимость решения задачи по повышению уровня производительности труда рабочего персонала, динамика которого изображена на рисунке 1.
Производительность труда означает объемы выработки продукции на одного сотрудника, что позволяет оценить эффективность трудовой деятельности и ее практическое значение при формировании финансовых результатов производственной деятельности предприятия. В периоде с 2014 по 2020 гг. уровень производительности труда российских предприятий увеличился с 25,6 долларов до 28,5 долларов. Данная тенденция роста неудовлетворительная, поскольку за последние года в мире наблюдается интенсивное развитие производственной деятельности и операционного управления бизнес-процессами.

В конечном итоге, эффективность трудовой деятельности персонала на предприятиях горнодобывающей промышленности России остается не высокой. По этой причине, реализация человеческого потенциала не высокая. Финансовые и экономические показатели/коэффициенты эффективности бизнес-деятельности автоматически снижаются, поскольку не удается в полном объеме использовать трудовой капитал. Из-за этого конкурентоспособность организации уменьшается.

Управление конкурентоспособностью организации подразумевает под собою систему, которая и управляет конкурентными преимуществами и недостатками 
фирмы, с целью повышения ее конкурентоспособности в сравнении с рыночными конкурентами [5].

Успешное функционирование и развитие предприятия требует соответствующего подхода к формированию его конкурентной стратегии, выявлению конкурентных преимуществ, а это в свою очередь предполагает необходимость определения роли и значения конкурентного потенциала в деятельности организации [6].

Одним из ключевых инструментов управления конкурентоспособности организации выступает формирование конкурентных преимуществ, которые свидетельствуют о превосходстве над конкурентами в экономической, технической и организационной сферах деятельности. С учетом наличия проблемы управления конкурентоспособностью из-за низкого уровня производительности труда во многих организациях горнодобывающей промышленности российской экономики, актуальным является разработка мероприятий по ее повышению. Среди действующих направлений - интеллектуализация труда.

Интеллектуализация труда - это процесс постоянного обогащения знаниями, приводящий к увеличению доли интеллектуального труда в деятельности человека. Интеллектуальная деятельность, как одна из разновидностей труда, направлена на изменение информации, присущей объектам окружающего мира. Главными условиями интеллектуализации труда являются образование и генетические особенности человека [7].

Подготовка нового поколения талантливых квалифицированных людей требует времени и огромных усилий, но именно длительное устойчивое инвестирование в интеллектуальный капитал предприятий горнодобывающей промышленности, которое гарантирует непрерывность инновационной активности, а также подготовка деятельных новаторов могут стать необходимой опорой для реализации оптимистичного сценария экономического развития данной отрасли национальной экономики России [8].

На сегодняшний день можно предложить следующие перспективные направления развития системы интеллектуализации труда, которые могут поспособствовать повышению качества труда и развития персонала, что выступает важнейшим способом в повышении конкурентоспособности на горнодобывающих предприятиях $[9 ; 10 ; 11]$ :

1. Необходимо совершенствование системы профессионального обучение персонала за счет средств организации.
Данный инструмент - хороший вариант для тех организаций, которые заинтересованы в повышении кадрового потенциала своих сотрудников. Профессиональное развитие персонала формирует надежду в завтрашнем дне. Такие сотрудники осознают, что ценность их, как человеческого капитала, будет возрастать.

2. Организация комфортного уровня корпоративной культуры и проведение мероприятий по командообразованию.

Люди - социальные институты, выступающие участниками активной внутриорганизационной коммуникации. Проводя большую часть времени на рабочем месте, рабочий персонал требует эффективный механизм замещения по обеспечению потребностей в общении.

3. Применение механизма социального диагностирования персонала.

Суть данной технологии заключается в постоянном мониторинге социальных проблем у сотрудников организации. В случае их выявления у отдельных работников, возникает необходимость в организации помощи в их решении. Нерешенные проблемы отражаются на психологическом состоянии человека и негативно влияют на эффективность его труда.

\section{4. Материальное стимулирование.}

При выстраивании системы материального стимулирования кадровой службой предприятия необходимо, с одной стороны,- заинтересовать персонала в общих результатах работы, с другой - учесть вклад каждого в этот общий результат.

Примером первого направления является определение той доли прибыли организации, которая пойдет на поощрение персонала.

Второе направление можно реализовать, сформировав целевые показатели для каждого сотрудника. Это можно сделать через систему ключевых показателей эффективности. Такая система позволяет оценивать эффективность труда каждого сотрудника индивидуально.

5. Применение адаптивного ассессмента, в основе которого лежит использования ассессмента-центра, как способа оценки рабочего персонала предприятия к развитию и инновациям.

6. Применение технологии искусственного интеллекта, которые будут активно применяться при подборе персонала, его обучении и развитии. 
7. Применение VR-технологии, которые будут активно применяться в рамках профессионального обучения, повышения квалификации и переориентации трудовых ресурсов на другие рабочие специальности.

Таким образом, вышеописанные мероприятия по повышению качества системы интеллектуализации труда рабочего персонала горнодобывающего предприятия способны достичь таких положительных результатов, как:

- рост производительности труда;

- стимулирование развития и обучения персонала;

- повышение уровня мотивации и вовлеченности персонала.

Таким образом, благодаря вышеперечисленным мероприятия, сотрудники организации будут удовлетворены своим местом работы, что сделает их привязку к рабочему месту и должности более крепкой. Тем самым, будут устранены угрозы текучести персонала и увольнения. А значит, кадровая политика и стратегия предприятия будут экономически эффективными.

По мнению Хасанова Г.Б. одним из путей развития системы интеллектуализации труда через профессиональное обучение персонала в современных условиях цифровизации российской экономики является создание у каждой компании учебного подразделения с функциями центра компетенций, дающего возможность управлять знаниями сотрудников, что позволит выявить и реализовать их интеллектуальный потенциал, способность генерировать инновации, повысить производительность труда и, следовательно, обеспечить конкурентоспособность бизнеса в современных условиях [12].

По мнению Рыбкиной М.В., Кангро М.В. и Пироговой Е.В. можно выделить следующие особенности цифровой трансформации рынка труда, приводящих к положительным изменениям роста производительности труда [13]:

- расширение дистанционных отношений, что приводит к децентрализации труда и занятости;

- формируется новая модель гибкого рынка труда, а устаревшая модель занятости исчезает;

- роботизация производства стимулирует экономический рост, что приводит к капитальным вложениям предприятий в новые объекты и бизнес-проекты.

Поскольку происходят такие кардинальные изменения на рынке труда, предприятиям важно проводить профессиональное обучение персонала с целью интел- лектуализации их трудовой деятельности по следующим направлениям:

1. Формирование владения навыков работы с цифровыми устройствами и технологиями, которые в дальнейшем станут неотъемлемым инструментов в трудовой деятельности.

2. Формирование новых компаний «будущего», особенностью которых является создание проектной команды на отдельный бизнес-проект, после реализации которых идет переключение на другие проектные группы и задачи.

3. Подготовка сотрудников к постоянной занятости на «удаленной основе», где необходимы отдельные навыки по управлению и решению трудовых задач.

Помимо этого, система профессионального обучения персонала будет ощущать изменения из-за:

- того, что технологии искусственного интеллекта активно внедряться в систему подбора персонала, его обучения и развития;

- того, что VR-технологии будут активно применяться в рамках профессионального обучения, повышения квалификации и переориентации трудовых ресурсов на другие рабочие специальности.

Таким образом, подводя итоги научной работы, можно прийти к следующим заключениям:

1. Эффективность трудовой деятельности персонала на предприятиях горнодобывающей промышленности России остается не высокой. По этой причине, реализация человеческого потенциала не высокая. Финансовые и экономические показатели/коэффициенты эффективности бизнес-деятельности автоматически снижаются, поскольку не удается в полном объеме использовать трудовой капитал. Из-за этого конкурентоспособность организации уменьшается.

2. С учетом наличия проблемы управления конкурентоспособностью из-за низкого уровня производительности труда во многих организациях горнодобывающей промышленности российской экономики, актуальным является разработка мероприятий по ее повышению. Среди действующих направлений - интеллектуализация труда.

3. Вышеописанные мероприятия по повышению качества системы интеллектуализации труда рабочего персонала горнодобывающего предприятия способны достичь таких положительных результатов, как рост производительности труда; стимулирование развития и обучения персонала; повышение уровня мотивации и вовлеченности персонала. 


\section{ЛИТЕРАТУРА}

1. Бутко Е.Я. Управление человеческими ресурсами // Образовательные ресурсы и технологии. 2016. № 5 (17).

2. Эффективность экономики России. URL: https://rosstat.gov.ru/folder/11186 (дата обращения: 17.10.2021).

3. Авдеев М.Ю. Актуальность проблемы управления производительностью труда на современном этапе // Вестник евразийской науки. 2019 . № 3.

4. Алейник А.А. Основные современные тенденции и проблемы НR-деятельности // Лидерство и менеджмент. 2019. № 1.

5. Емадаков Р.Ю. Анализ факторов формирования конкурентоспособности предприятия // Вестник Марийского государственного университета. Серия «Сельскохозяйственные науки. Экономические науки». 2018. № 1 (13).

6. Войнов Д.А., Германович А.Г. Управление конкурентоспособностью предприятия // Международный журнал прикладных наук и технологий «Integral». 2019. № 2.

7. Бойко А.Н. Место и роль интеллектуализация труда в обеспечении мирового инновационного развития // Вестник Северо-Кавказского федерального университета. 2020. № 6 (81). С. 55-61.

8. Шацкая И.В. Проблема интеллектуализации труда в постиндустриальном обществе // Современные исследования проблем управления кадровыми ресурсами. 2018. С. 216-221.

9. К Кознов А.Б. Влияние цифровизации на рынок труда // Международный журнал гуманитарных и естественных наук. 2019. № 4-2. С. 177-179.

10. Кондаков М.В. Современные тенденции и перспективы развития российского рынка труда // XI международный молодежный форум «0бразование. Наука. Производство». 2019. С. 2061-2066.

11. Бельчик Т.А. Повышение производительности труда как основной фактор экономического роста // Вестник Кемеровского государственного университета. Серия: Политические, социологические и экономические науки. 2017. № 2 (4). С. 29-33.

12. Хасанова Г.Б. Корпоративное образование как инструмент управления знаниями в условиях цифровизации // КПЖ. 2019. № 5 (136).

13. Рыбкина М.В., Кангро М.В., Пирогова Е.В. Развитие рынка труда в условиях становления цифровой экономики // Вестник ГуУ. 2019. № 11. С. 36-41.

(с) Изосимов Никита Павлович ( Nikitaizosimov@gmail.com ).

Журнал «Современная наука: актуальные проблемы теории и практики»

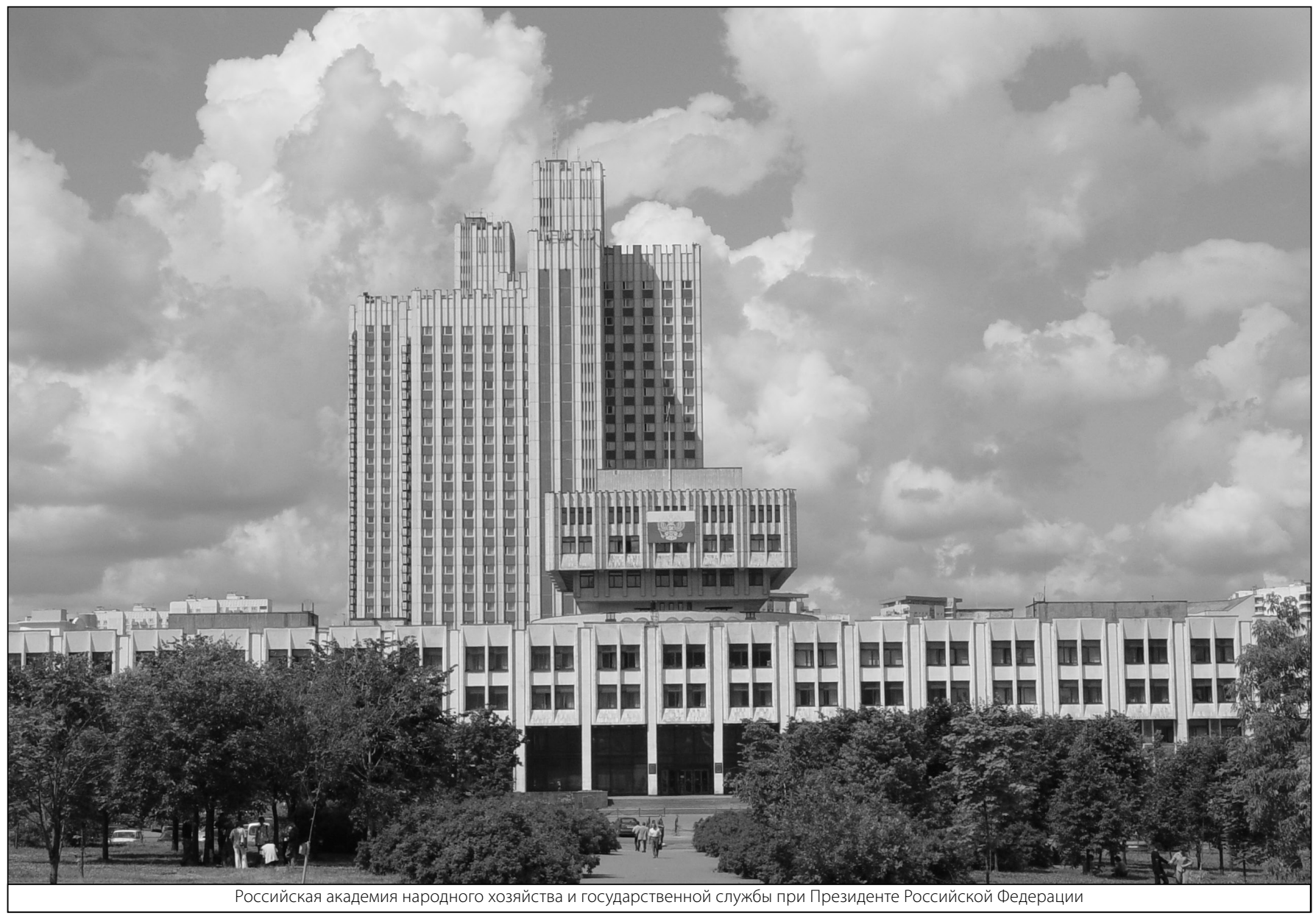

